\title{
Pathogenesis and Management of Apnea of Prematurity: A Brief Overview
}

\section{Prem Arora*}

The Carman and Ann Adams Department of Pediatrics, Division of Neonatal-Perinatal Medicine, Wayne State University School of Medicine, Detroit Medical Center, Children's Hospital of Michigan, Detroit, Michigan, USA

Apnea of prematurity is defined as sudden cessation of breathing in an infant younger than 37 weeks' gestational age lasting for more than 20 seconds, or for shorter duration if accompanied by bradycardia and/ or oxygen desaturation [1]. It is a developmental disorder that results from physiologic immaturity of the respiratory control system in preterm infants [2]. Lower the gestational age, higher is the incidence and severity of apnea of prematurity [3]. Apneic episodes in preterm infants may be central (absent inspiratory efforts), obstructive (airway obstruction with present inspiratory efforts), or mixed (combination of central and obstructive mechanisms), with latter being the most common form [4].

Regular rhythmic breathing requires a patent airway, central respiratory drive originating from respiratory centers in the brainstem modulated by input from peripheral neural and chemical receptors, and coordinated effective functioning of the muscles of respiration. Changes in arterial $\mathrm{PCO}_{2}, \mathrm{PO}_{2}$, and $\mathrm{pH}$ acts on neural and chemical receptors and inputs from these centers are integrated by the respiratory center in brainstem, which then send signals to the respiratory muscles to maintain airway patency and regulate the level of ventilation. The immature brainstem respiratory centers in preterm infants have an attenuated response to carbon dioxide and a paradoxical response to hypoxia that results in apnea rather than the hyperventilation observed in term infants and adults [2,5-7]. This immaturity of breathing responses affects central and peripheral chemosensitivity, and inhibitory pulmonary afferents resulting not only in attenuated responses to hypoxia and hypercapnia, but also an exaggerated inhibitory response to stimulation of airway receptors $[2,9,10]$. Anatomically, the immaturity of preterm brain is manifested as decreased number of synaptic connections, decreased dendritic arborization and poor myelination [2]. Functional immaturity is manifested by impaired brainstem auditory evoked responses in infants with apnea of prematurity indicating increased brainstem conduction time, that improves after treatment with aminophylline [11].

Obstructive apnea in preterm neonates may result from poor pharyngeal tone causing pharyngeal collapse with the negative airway pressures generated during inspiration, or it may result from incoordination of the upper airway muscles involved in maintaining airway patency due to immaturity of the neuronal signaling mechanisms [12]. Frequent use of nasal catheters and prongs in preterm infants may produce swelling of the nasal mucosa leading to nasal obstruction that may cause obstructive apnea in these obligate nasal breathers [13].

Possible role of genetic factors in causation of apnea of prematurity is suggested by higher odds of its occurrence in premature infants born to first-degree consanguineous parents [14], and by a high concordance rate among monozygotic twin pairs [15]. The exact genes or genetic factors responsible for apnea of prematurity have not yet been fully elucidated.

Although attributed to prematurity in majority of the cases, apnea of prematurity is a diagnosis of exclusion and therefore, a thorough evaluation for secondary causes such as sepsis of the newborn, necrotizing enterocolitis, intraventricular hemorrhage, maternal use of opiate or magnesium sulfate, anemia, hypothermia, hypoglycemia etc, should be performed depending upon the clinical presentation, especially when it occurs for the first time after the $2^{\text {nd }}$ week of life in a previously well infant, or in an infant who was not having any episodes for more than 5-7 days $[16,17]$.

The management of apnea of prematurity starts with eliminating the factors that increase the risk of apnea such as maintenance of a stable thermal environment and nasal patency, and avoidance of extreme neck flexion and extension $[17,18]$. In preterm infants with obstructive or mixed apnea, nasal continuous positive pressure (CPAP) or oxygen/ air flow through a nasal canula may help to decrease the frequency and severity of episodes [16-18]. Methylxanthine therapy especially with caffeine has been shown to be effective in the treatment of symptomatic preterm infants with apnea of prematurity, due to its ability to cause central nervous system stimulation by competitive inhibition of adenosine receptors [19]. Caffeine is preferred over theophylline because of its longer half-life and a lower incidence of adverse effects [20]. It is given as a loading dose of $20 \mathrm{mg} / \mathrm{kg}$ of caffeine citrate orally or intravenously over 30 minutes, followed by a daily maintenance dose of 5 to $8 \mathrm{mg} / \mathrm{kg}$ per dose either orally or intravenously $[16,18]$. In infants with persistent apneic episodes, an additional loading dose of caffeine citrate $(10 \mathrm{mg} / \mathrm{kg})$ may be given followed by an increase in the daily maintenance dose by 20 percent $[16,18]$. Caffeine has been shown to have a beneficial effect not only for apnea of prematurity, but for other neonatal morbidities such as bronchopulmonary dysplasia, patent ductus arteriousus, and post-operative apnea as well [19,21]. It has been shown to decrease time on mechanical ventilation and the need for oxygen therapy [19,21]. The major 'caffeine for apnea of prematurity (CAP) trial' demonstrated improved outcomes at 18 to 21 months, including clinically significant decreases in cerebral palsy and cognitive impairment in the babies who received caffeine during the neonatal period [22]. However, in a recently published follow-up of these infants, neonatal caffeine therapy was shown to be no longer associated with a significantly improved rate of survival without disability in children with very low birth weights when assessed at 5 years [23]. Despite this, the immediate benefits associated with the use of caffeine for apnea of prematurity still warrant its use in these symptomatic preterm infants.

Infants with secondary causes identified on investigations should be treated accordingly. Despite the conflicting evidence [24], some

*Corresponding author: Prem Arora, MD, FAAP, The Carman and Ann Adams Department of Pediatrics, Division of Neonatal-Perinatal Medicine, Children's Hospital of Michigan, Detroit, MI 48201, USA, Tel: (313) 418-9624; E-mail: parora@dmc.org

Received March 14, 2012; Accepted March 16, 2012; Published March 20, 2012

Citation: Arora P (2012) Pathogenesis and Management of Apnea of Prematurity A Brief Overview. J Neonatal Bio 1:e104. doi:10.4172/2167-0897.1000e104

Copyright: (c) 2012 Arora P. This is an open-access article distributed under the terms of the Creative Commons Attribution License, which permits unrestricted use, distribution, and reproduction in any medium, provided the original author and source are credited. 
Citation: Arora P (2012) Pathogenesis and Management of Apnea of Prematurity: A Brief Overview. J Neonatal Bio 1:e104. doi:10.4172/2167$0897.1000 \mathrm{e} 104$

investigators recommend packed red blood cell transfusions for infants with persistent apneic episodes with hematocrit below 25\%. However, clinical judgment should be used in these anemic infants, especially in view of recent concerns of increased risk of necrotizing enterocolitis and transfusion related acute gut injury (TRAGI) in preterm infants who received blood transfusions [25].

Apnea of prematurity usually resolves by 36 weeks postmenstrual age and infants who remain free of apneic episodes for seven days after discontinuation of caffeine therapy, may be discharged home without a cardiorespiratory monitor [16-18]. After proper teaching of the parents, home cardio respiratory monitoring may be considered in infants who continue to have milder episodes (not associated with major bardycardia or oxygen destauration) at the time of discharge [16-18].

\section{References}

1. Committee on Fetus and Newborn. American Academy of Pediatrics (2003) Apnea, sudden infant death syndrome, and home monitoring. Pediatrics 111: 914-917.

2. Mathew OP (2011) Apnea of prematurity: pathogenesis and management strategies. J Perinatol 31: 302-310.

3. Henderson-Smart DJ (1981) The effect of gestational age on the incidence and duration of recurrent apnoea in newborn babies. Aust Paediatr J 17: 273276 .

4. Finer NN, Barrington KJ, Hayes BJ, Hugh A (1992) Obstructive, mixed, and central apnea in the neonate: physiologic correlates. J Pediatr 121: 943-950.

5. Noble LM, Carlo WA, Miller MJ, DiFiore JM, Martin RJ (1987) Transient changes in expiratory time during hypercapnia in premature infants. J Appl Physiol 62: 1010-1013.

6. Martin RJ, Carlo WA, Robertson SS, Day WR, Bruce EN (1985) Biphasic response of respiratory frequency to hypercapnea in preterm infants. Pediatr Res 19: 791-796.

7. Rigatto H, Brady JP, de la Torre Verduzco R (1975) Chemoreceptor reflexes in preterm infants: II. The effect of gestational and postnatal age on the ventilatory response to inhaled carbon dioxide. Pediatrics 55: 614-620.

8. Khan A, Qurashi M, Kwiatkowski K, Cates D, Rigatto H (2005) Measurement of the $\mathrm{CO} 2$ apneic threshold in newborn infants: possible relevance for periodic breathing and apnea. J Appl Physiol 98: 1171-1176.

9. Rigatto H, Brady JP, de la Torre Verduzco R (1975) Chemoreceptor reflexes in preterm infants: I. The effect of gestational and postnatal age on the ventilatory response to inhalation of $100 \%$ and $15 \%$ oxygen. Pediatrics 55 : 604-613.
10. Alvaro R, Alvarez J, Kwiatkowski K, Cates D, Rigatto H (1992) Small preterm infants (less than or equal to $1500 \mathrm{~g}$ ) have only a sustained decrease in ventilation in response to hypoxia. Pediatr Res 32: 403-406.

11. Chen YJ, Liou CS, Tsai CH, Yeh TF (1994) Effect of aminophylline on brain stem auditory evoked potentials in preterm infants. Arch Dis Child Fetal Neonatal Ed 71: F20-23.

12. Reed WR, Roberts JL, Thach BT (1985) Factors influencing regional patency and configuration of the human infant upper airway. J Appl Physiol 58: 635644.

13. Miller MJ, Martin RJ, Carlo WA, Fouke JM, Strohl KP, et al. (1985) Oral breathing in newborn infants. J Pediatr 107: 465-469.

14. Tamim H, Khogali M, Beydoun H, Melki I, Yunis K, et al. (2003) Consanguinity and apnea of prematurity. Am J Epidemiol 158: 942-946.

15. Bloch-Salisbury E, Hall MH, Sharma P, Boyd T, Bednarek F, et al. (2010) Heritability of apnea of prematurity: a retrospective twin study. Pediatrics 126 e779-787.

16. Mishra S, Agarwal R, Jeevasankar M, Aggarwal R, Deorari AK, et al. (2008) Apnea in the newborn. Indian J Pediatr 75: 57-61.

17. Stokowski LA (2005) A primer on Apnea of prematurity. Adv Neonatal Care 5: $155-170$.

18. Bhatt-Mehta V, Schumacher RE (2003) Treatment of apnea of prematurity. Paediatr Drugs 5: 195-210.

19. Schmidt B, Roberts RS, Davis P, Doyle LW, Barrington KJ, et al. (2006) Caffeine therapy for apnea of prematurity. N Engl J Med 354: 2112-2121.

20. Henderson-Smart DJ, Steer PA (2010) Caffeine versus theophylline for apnea in preterm infants. Cochrane Database Syst Rev (1): CD000273.

21. Aranda JV, Beharry K, Valencia GB, Natarajan G, Davis J (2010) Caffeine impact on neonatal morbidities. J Matern Fetal Neonatal Med 3: 20-23.

22. Schmidt B, Roberts RS, Davis P, Doyle LW, Barrington KJ, et al. (2007) Longterm effects of caffeine therapy for apnea of prematurity. N Engl J Med 357: 1893-1902.

23. Schmidt B, Anderson PJ, Doyle LW, Dewey D, Grunau RE, et al. (2012) Survival without disability to age 5 years after neonatal caffeine therapy for apnea of prematurity. JAMA 307: 275-282.

24. Westkamp E, Soditt V, Adrian S, Bohnhorst B, Groneck P, et al. (2002) Blood transfusion in anemic infants with apnea of prematurity. Biol Neonate 82 228-232.

25. Paul DA, Mackley A, Novitsky A, Zhao Y, Brooks A, et al. (2011) Increased odds of necrotizing enterocolitis after transfusion of red blood cells in premature infants. Pediatrics 127: 635-641. 